\title{
Pseudorotaxanes and Rotaxanes Formed by Viologen Derivatives
}

\author{
Adam B. Braunschweig, ${ }^{[a]}$ Célia M. Ronconi, ${ }^{[a]}$ Ja-Young Han, ${ }^{[a]}$ Fabio Aricó, ${ }^{\text {[a] }}$ \\ Stuart J. Cantrill, ${ }^{[a]}$ J. Fraser Stoddart, ${ }^{*[a]}$ Saeed I. Khan, ${ }^{[a]}$ Andrew J. P. White, ${ }^{[b]}$ and \\ David J. Williams ${ }^{[b]}$
} Keywords: [2]Rotaxanes / Isothermal titration microcalorimetry / Noncovalent interactions / Host-guest system / Nano-
technology

\begin{abstract}
Dibenzyl-4,4'-bipyridinium $\quad\left(\right.$ BIPY $\left.^{2+}\right)$ bis(hexafluorophosphate) and three of its derivatives - disubstituted at the para positions of the benzyl groups with $\mathrm{CO}_{2} \mathrm{Me}, \mathrm{F}$, and $\mathrm{Me}$ in turn - have been shown to form 1:1 complexes that are [2]pseudorotaxanes with dibenzo[24]crown-8 (DB24C8), benzometaphenylene[25]crown-8 (BMP25C8), and dipyrido[24]crown-8 (DP24C8) in $\mathrm{CD}_{3} \mathrm{CN}$ solution by ${ }^{1} \mathrm{H}$ NMR spectroscopy and in one case in the solid state by X-ray crystallography. Binding constants $\left(K_{a}\right)$ for all of these 1:1 complexes, which were determined both (1) by isothermal titration calorimetry in MeCN solution and (2) by the ${ }^{1} \mathrm{H}$ NMR spectroscopic single-point method in $\mathrm{CD}_{3} \mathrm{CN}$ solution, were found to be, on the average, an order of magnitude less than the $K_{\mathrm{a}}$ values obtained for DB24C8 and DP24C8 with dibenzylammonium $\left(\mathbf{D B A}^{+}\right.$) hexafluorophosphate and three of its derivatives, also disubstituted at the para positions of the benzyl groups with $\mathrm{CO}_{2} \mathrm{Me}, \mathrm{F}$ and $\mathrm{Me}$. In the case of
\end{abstract}

BMP25C8, however, the $K_{a}$ values with both categories (BIPY $^{2+}$ and DBA $^{+}$) of guests are much of a muchness, being both small and error prone. The equilibrium thermodynamics for these small libraries of [2]pseudorotaxanes indicate that the best bistable [2]rotaxanes incorporating both $\mathbf{D B A}{ }^{+}$and $\mathbf{B I P Y}^{2+}$ recognition sites are going to involve ester functions in their dumbbell components and will employ DP24C8 or, failing that, DB24C8 as the ring component. The BIPY ${ }^{2+}$ threads also directed the templated assembly of [2]rotaxanes incorporating the crown ethers (DB24C8, DP24C8, and BMP25C8) and triphenylphosphonium stoppers using the threading followed by stoppering approach. The rotaxanes were characterized in solution by ${ }^{1} \mathrm{H}$ NMR spectroscopy, and in one case, in the solid state by X-ray crystallography.

(๔ Wiley-VCH Verlag GmbH \& Co. KGaA, 69451 Weinheim, Germany, 2006)

\section{Introduction}

The ability to thread secondary dibenzylammonium ions $\left(\mathbf{D B A}^{+}\right)$through appropriately sized macrocyclic polyethers has resulted in the creation of numerous supramolecular assemblies, ${ }^{[1]}$ as well as interlocked molecules, ${ }^{[2]}$ some of which have been shown to function as nanoscale machines ${ }^{[3]}$ and switches. ${ }^{[4]}$ The bistability observed in some of these device-like systems is achieved by providing a secondary recognition site around which a crown ether may reside $-\mathrm{a}$ role that has been ably filled ${ }^{[3 \mathrm{a}, 3 \mathrm{~b}, 4 \mathrm{a}]}$ by viologen moieties - should the ammonium ion-recognition be "turned off" upon deprotonation. The rational design of such switching systems must exploit the relative binding affinities that these different (di)cationic "stations" exhibit to-

[a] The California NanoSystems Institute and Department of Chemistry and Biochemistry, University of California, Los Angeles,

405 Hilgard Avenue, Los Angeles, CA 90095-1569, USA Fax: +1-310-206-1843 E-mail: stoddart@chem.ucla.edu

[b] Chemical Crystallography Laboratory, Department of Chemistry, Imperial College,

South Kensington, London SW7 2AY, UK

$\square$ Supporting information for this article is available on the WWW under http://www.eurjoc.org or from the author. ward different polyether macrocycles. ${ }^{[5]}$ A closely related system has been studied by Loeb and co-workers, ${ }^{[6-8]}$ in which bipyridinium ethane dications are shown to bind ${ }^{[6]}$ crown ethers that have a [24]crown- 8 constitution. This recognition pair has subsequently been utilized in the formation of both catenanes ${ }^{[7]}$ and rotaxanes. ${ }^{[8]}$ Although the binding properties of various substituted secondary dialkylammonium ions with crown ethers have been reported, ${ }^{[9]}$ the experimental parameters often differ significantly from case to case - i.e., solvent, concentration, temperature, and method of sample interrogation (NMR spectroscopy, UV/ Vis spectroscopy, calorimetry) - rendering comparisons difficult, if not circumspect. To compare legitimately the association of both dibenzylammonium $\left(\mathbf{D B A}^{+}\right)$and bipyridinium $\left(\mathbf{B I P Y}^{2+}\right)$ ions with a range of crown ethers, we describe in this full paper their binding characteristics, under a standard set of conditions, using two contrasting techniques, namely, the single-point method by ${ }^{1} \mathrm{H}$ NMR spectroscopy ${ }^{[10]}$ and isothermal titration calorimetry (ITC). ${ }^{[11]}$ Stimulated by the binding ability of $24 \mathrm{C} 8$ and $25 \mathrm{C} 8$ constituted crowns with different thread-shaped components containing $\mathbf{B I P Y}^{2+}$ units in $\mathrm{MeCN}$, we report herein an easy one-step procedure to synthesize [2]rotaxanes incorporating the newly studied $\mathbf{B I P Y}{ }^{2+}$ dications as the sole template and 

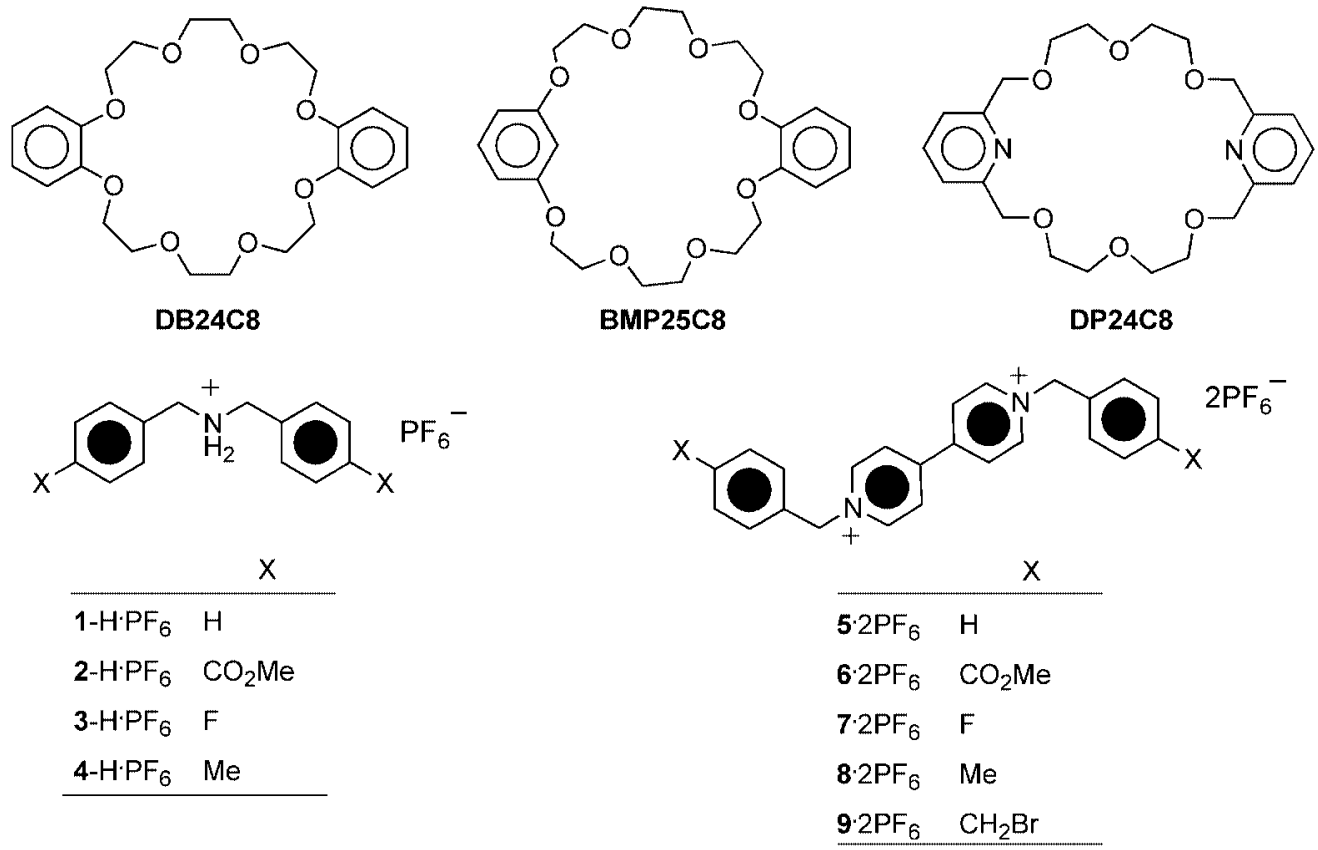

Figure 1. Structural formulas of the macrocyclic polyethers, the dibenzylammonium (DBA ${ }^{+}$) hexafluorophosphate and bipyridium $\left(\right.$ BIPY $\left.^{2+}\right)$ hexafluorophosphate salts.

three different crowns - namely, dibenzo[24]crown-8 (DB24C8), benzometaphenylene[25]crown-8 (BMP25C8) and dipyrido[24]crown-8 (DP24C8) - using threadingfollowed-by-stoppering (Figure 1).

\section{Results and Discussion}

\section{Synthesis of Crowns and Threads}

Dibenzylammonium salts $\mathbf{1}-\mathbf{H} \cdot \mathbf{P F}_{6},{ }^{[9 \mathrm{a}]} \mathbf{2}-\mathbf{H} \cdot \mathbf{P F}_{6},{ }^{[9 \mathrm{c}]} \mathbf{3}$ $\mathbf{H} \cdot \mathbf{P F}_{6}{ }^{[9 \mathrm{f}]}$ and $\mathbf{4}-\mathbf{H} \cdot \mathbf{P F}_{6},{ }^{[9 \mathrm{~b}]}$ as well as the crown ethers DP24C8 ${ }^{[9 e]}$ and BMP25C8, ${ }^{[9 e]}$ were synthesized as previously reported. See Figure 1 for their structural formulas. The general synthetic pathway that leads to the formation of the viologen derivatives $\mathbf{5} \cdot 2 \mathrm{PF}_{6},{ }^{[12]} \mathbf{6} \cdot 2 \mathrm{PF}_{6}, \mathbf{7} \cdot 2 \mathrm{PF}_{6}$, $\mathbf{8} \cdot 2 \mathrm{PF}_{6},{ }^{[13]}$ and $\mathbf{9} \cdot 2 \mathrm{PF}_{6}{ }^{[14]}$ containing bipyridinium $\left(\mathbf{B I P Y}^{\mathbf{2 +}}\right.$ ) units is depicted in Scheme 1. Each substitution reaction of the functionalized benzyl bromide with $4,4^{\prime}$-bipyridine in $\mathrm{MeCN}$ resulted in a yellow precipitate. The yellow solids, which are the bromide salts of the viologen derivatives, were collected by filtration and subjected to counterion exchange by dissolving them in hot water and precipitating with saturated aqueous $\mathrm{NH}_{4} \mathrm{PF}_{6}$ to afford the corresponding white hexafluorophosphate salts.

\section{Pseudorotaxane Formation}

Preliminary studies on the binding interactions between the viologen salts with the three crown ethers were conducted using mass spectrometric analysis. Solutions containing equimolar quantities of guest and crown ether were subjected to fast atom bombardment mass spectrometry (FABMS). ${ }^{[15]}$ In each case, the mass spectra had $\mathrm{m} / \mathrm{z}$ peaks corresponding to free crown ether, free guest, and the 1:1

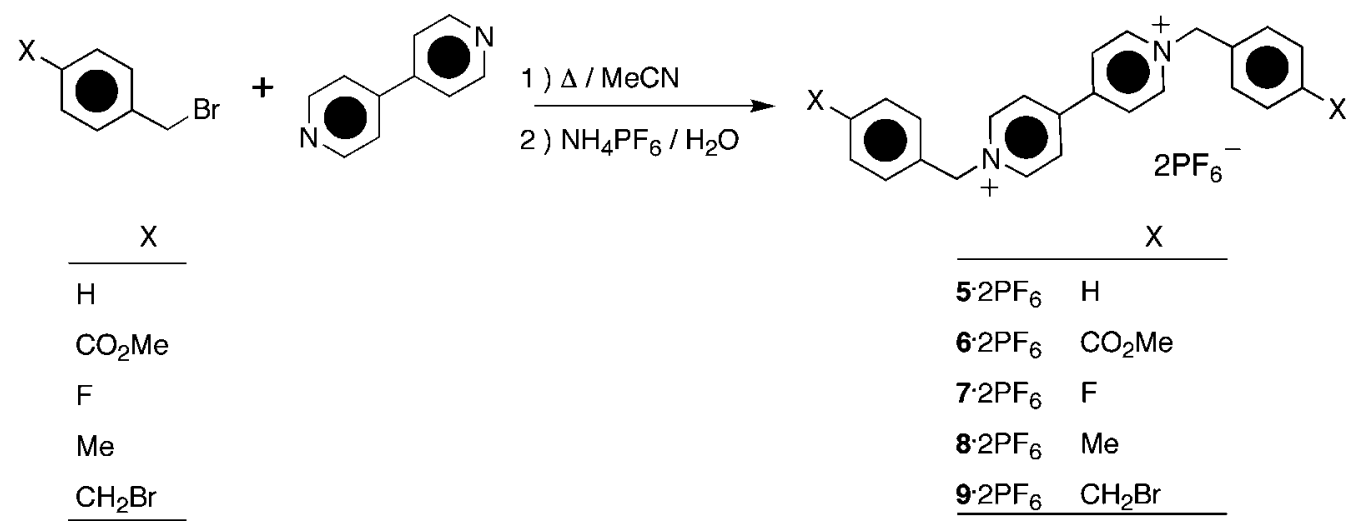

Scheme 1. Synthesis of the viologen derivatives. 
complex formed between the host and guest. The presence of the peaks corresponding to the $1: 1$ complex between the macrocycle and the viologen derivative imply the presence of binding interactions between crown ethers and viologens in the gas phase; mass spectrometry, however, does not give any details regarding the geometry of the complexes formed.

Nonetheless, strong literature ${ }^{[16]}$ and X-ray crystallographic ${ }^{[15]}$ evidence supports a threaded complex in which the viologen's guest resides within the cavity of the macrocycle, thus forming a [2]pseudorotaxane. X-ray quality single crystals of the $\mathrm{DP} 24 \mathrm{C} 8 \subset \mathbf{6} \cdot 2 \mathrm{PF}_{6}$ complex were grown by layer diffusion of $i \mathrm{Pr}_{2} \mathrm{O}$ into a 1:1 equimolar $\mathrm{MeCN}$ solution of the components. The solid-state superstructure (Figure 2) reveals that the small DP24C8 ring encircles the bulky $6 \cdot 2 \mathrm{PF}_{6}$ guest. The binding is mediated by a combination of $[\pi \cdots \pi],[\mathrm{C}-\mathrm{H} \cdots \mathrm{O}]$ and $[\mathrm{C}-\mathrm{H} \cdots \pi]$ bonding interactions. The DP24C8 ring in the complex adopts a very different conformation from that observed ${ }^{[9 \mathrm{e}]}$ for the free crown ether. Because the free crown ether in the solid state is linked together to a neighboring ring by hydrogen bonding to form a centrosymmetrically related pair of DP24C8 molecules, the DP24C8 component of the [2]pseudorotaxane adopts a Z-like conformation, where the nitrogen atoms on the two pyridyl rings are facing each other. Moreover, the solid-state superstructure confirms that the 1:1 complex

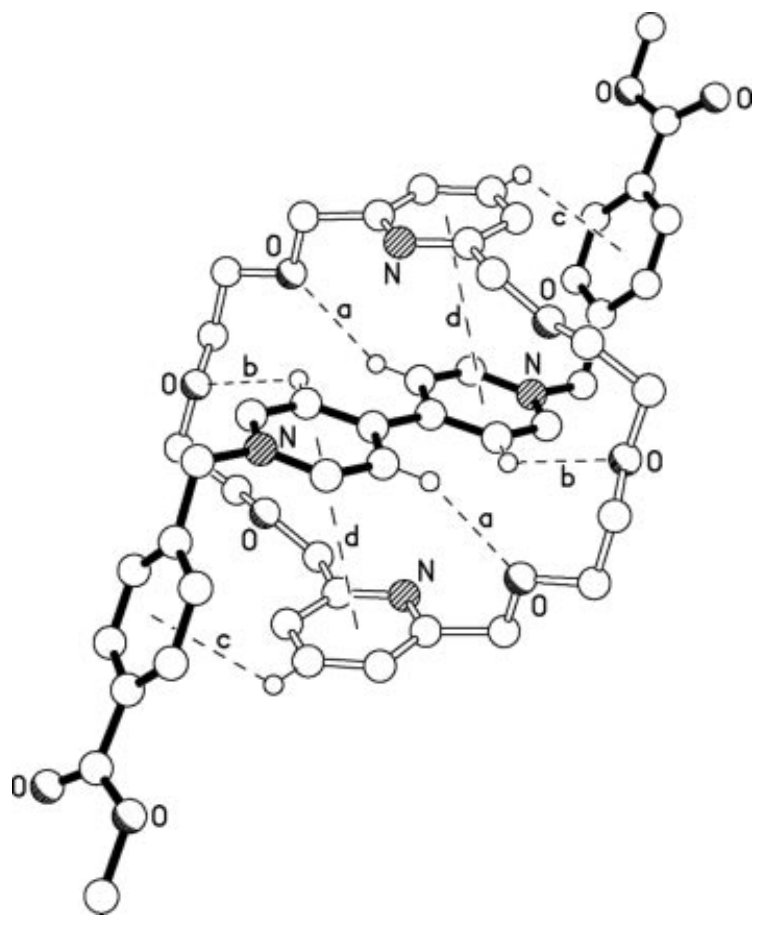

Figure 2. The molecular superstructure of the dicationic $C_{i}$-symmetric 1:1 complex formed between DP24C8 and $\mathbf{6} \cdot 2 \mathrm{PF}_{6}$ showing the intra-[2]pseudorotaxane noncovalent bonding interactions. The hydrogen-bond geometries, $[\mathrm{C} \cdots \mathrm{O}],[\mathrm{H} \cdots \mathrm{O}][\AA],[\mathrm{C}-\mathrm{H} \cdots \mathrm{O}]\left[^{\circ}\right]$ are (a) $3.34,2.48,150$; (b) $3.27,2.58,129$. The $[\mathrm{C}-\mathrm{H} \cdots \pi]$ interaction (c) has an $\mathrm{H} \cdots \pi$ separation of $3.01 \AA$, and a $\mathrm{C}-\mathrm{H} \cdots \pi$ angle of $128^{\circ}$. The $\pi-\pi$ stacking interaction (d) has centroid...centroid and mean interplanar separations of 3.83 and $3.42 \AA$, respectively, the rings being inclined by ca. $16^{\circ}$. formed between the macrocycle and the viologen derivative is assembled in a threaded host-guest fashion.

Previously, the binding constants $\left(K_{\mathrm{a}}\right)$ for the $1: 1 \mathrm{com}$ plexes, $\mathbf{1 - H} \cdot \mathrm{PF}_{6} \subset \mathbf{D B} 24 \mathbf{C 8},{ }^{\left[{ }^{9 \mathrm{c}}\right]} \mathbf{1 - H} \cdot \mathrm{PF}_{6} \subset \mathrm{DP} \mathbf{2 4 C 8},{ }^{[9 \mathrm{e}]} \mathbf{1 - H} \cdot$ $\mathrm{PF}_{6} \subset \mathbf{B M P 2 5 C 8},{ }^{\left[{ }^{[\mathrm{e}}\right]} \quad \mathbf{2 - H} \cdot \mathrm{PF}_{6} \subset \mathrm{DB} 24 \mathrm{C8},{ }^{\left[{ }^{[9}\right]} \quad \mathbf{2}-\mathrm{H} \cdot \mathrm{PF}_{6} \subset$ DP24C8, ${ }^{[9 \mathrm{e}]} \mathbf{2}-\mathbf{H} \cdot \mathrm{PF}_{6} \subset \mathbf{B M P 2 5 C 8},{ }^{\left[{ }^{9 \mathrm{c}}\right]} \mathbf{3}-\mathbf{H} \cdot \mathrm{PF}_{6} \subset \mathbf{D B 2 4 C 8}{ }^{[9 \mathrm{f}]}$ and $\mathbf{4}-\mathbf{H} \cdot \mathrm{PF}_{6} \subset \mathbf{D B} 24 \mathbf{C 8}^{[9 \mathrm{c}]}$ had been determined using the single-point method, whereas in this study, all binding studies were carried out by ITC (Table 1) and compared, wherever possible, to literature values reported previously. In the case of complexes formed between the $\mathbf{D B} \mathbf{A}^{+}$cations and DB24C8, DP24C8, and BMP25C8 crowns, for which binding constants had already been obtained, the ITC results are in good agreement with the previously recorded $K_{\mathrm{a}}$ values obtained by the ${ }^{1} \mathrm{H}$ NMR spectroscopic single-point method (Table 1). Some general observations can be made from the $K_{\mathrm{a}}$ values determined by ITC. The poor binding affinities of BMP25C8 with the $\mathbf{D B A}^{+}$guests is the result of disrupting the $[\mathrm{O}-\mathrm{C}-\mathrm{C}-\mathrm{O}]$ geometry. ${ }^{[9 \mathrm{~b}]}$ The lower binding affinities of DB24C8 and DP24C8 for BIPY ${ }^{2+}$ guests than for $\mathbf{D B} \mathbf{A}^{+}$guests is both the result of steric and electronic interactions that are less favorable than the interactions in [2]pseudorotaxanes with the $\mathbf{D B} \mathbf{A}^{+}$guests. The complexes formed by the $\mathbf{D B 2 4 C 8}$ and the $\mathbf{D B A}^{+}$guests are stabilized primarily by $\left[\mathrm{N}^{+}-\mathrm{H} \cdots \mathrm{O}\right]$ hydrogen bonds, aided by weaker $[\mathrm{C}-\mathrm{H} \cdots \mathrm{O}]$ and $[\pi \cdots \pi]$ interactions between the ion center and the macrocyclic polyethers. The viologen guests are complexed in a fashion such that the crown ether encircles the guests, so that there is $[\mathrm{C}-\mathrm{H} \cdots \mathrm{O}]$ hydrogen bonding as

Table 1 . The stability constants $\left(K_{\mathrm{a}}\right)$ for the [2]pseudorotaxanes $(1: 1$ complexes) formed in MeCN solutions at $298 \mathrm{~K}$ between DB24C8, BMP25C8 and DP24C8 and the dibenzylbipyridinium guests 5 $8 \cdot 2 \mathrm{PF}_{6}$, and also by way of comparison, the dibenzylammonium guests $\mathbf{1}-\mathbf{H}-\mathbf{4}-\mathbf{H} \cdot \mathrm{PF}_{6}$, as determined by isothermal titration microcalorimetry (ITC).

\begin{tabular}{|c|c|c|c|c|}
\hline \multirow[t]{3}{*}{ Guest } & \multirow[t]{3}{*}{$X$} & \multicolumn{3}{|c|}{ Crown } \\
\hline & & DB24C8 & DP24C8 & BMP25C8 \\
\hline & & $K_{\mathrm{a}}\left[\mathrm{M}^{-1}\right]^{[\mathrm{a}]}$ & $K_{\mathrm{a}}\left[\mathrm{M}^{-1}\right]^{[\mathrm{a}]}$ & $K_{\mathrm{a}}\left[\mathrm{M}^{-1}\right]^{[\mathrm{a}]}$ \\
\hline $1-\mathrm{H} \cdot \mathrm{PF}_{6}$ & $\mathrm{H}$ & $237 \pm 112^{[b]}$ & $575 \pm 163^{[\mathrm{c}]}$ & $19 \pm 7^{[\mathrm{d}]}$ \\
\hline $\mathbf{2}-\mathbf{H} \cdot \mathrm{PF}_{6}$ & $\mathrm{CO}_{2} \mathrm{Me}$ & $1265 \pm 7^{[\mathrm{e}]}$ & $1920 \pm 424^{[\mathrm{f}]}$ & $30 \pm 3^{[\mathrm{g}]}$ \\
\hline $3-\mathbf{H} \cdot \mathrm{PF}_{6}$ & $\mathrm{~F}$ & $495 \pm 65^{[\mathrm{h}]}$ & $1125 \pm 92$ & $34 \pm 8$ \\
\hline $4-\mathrm{H} \cdot \mathrm{PF}_{6}$ & $\mathrm{Me}$ & $243 \pm 9^{[i]}$ & $362 \pm 54$ & $24 \pm 5$ \\
\hline $\mathbf{5} \cdot 2 \mathrm{PF}_{6}$ & $\mathrm{H}$ & $82 \pm 16$ & $95 \pm 4$ & $67 \pm 10$ \\
\hline $6 \cdot 2 \mathrm{PF}_{6}$ & $\mathrm{CO}_{2} \mathrm{Me}$ & $71 \pm 29$ & $89 \pm 19$ & $69 \pm 8$ \\
\hline $7 \cdot 2 \mathrm{PF}_{6}$ & $\mathrm{~F}$ & $72 \pm 18$ & $103 \pm 28$ & $64 \pm 11$ \\
\hline $8 \cdot 2 \mathrm{PF}_{6}$ & $\mathrm{Me}$ & $78 \pm 2$ & $77 \pm 11$ & $71 \pm 2$ \\
\hline
\end{tabular}

[a] Fits were performed using software provided by Microcal LLC software, and the stoichiometry of all complexes was between 0.93 and 1.07 , which indicates that a 1:1 complex was formed. [b] The binding constant has been previously reported as $320 \mathrm{M}^{-1}$, see ref. ${ }^{[9 c]}$. [c] The binding constant for this system could not be measured accurately by the single-point method, see ref. ${ }^{[9]}$. [d] The binding constant could not be attained by the single-point method, see ref. ${ }^{[9 c]}$. [e] The binding constant has been previously reported as $1100 \mathrm{M}^{-1}$, see ref. ${ }^{[9 \mathrm{c}]}$. [f] The binding constant has been previously reported as $1700 \mathrm{M}^{-1}$, see ref. ${ }^{[9 \mathrm{e}]}$. [g] The binding constant for this system has been previously reported as $<100 \mathrm{M}^{-1}$, see ref. ${ }^{[9 c]}$. [h] The binding constant for system has been previously reported as $875 \mathrm{M}^{-1}$, see ref. ${ }^{[9 f]}$. [i] The binding constant for this system has been previously reported as $170 \mathrm{M}^{-1}$, see ref. ${ }^{[9 \mathrm{c}]}$. 
well as optimal $[\pi \cdots \pi]$ stacking between the two, which together are weaker interactions than is the charge stabilization present in the $\mathbf{D B} \mathbf{A}^{+}$-based [2]pseudorotaxanes with the crowns DB24C8 and DP24C8. ${ }^{[17]}$ The data also suggest that BMP25C8 complexes $\mathbf{B I P Y}^{\mathbf{2}}$ guests as strongly as it does $\mathbf{D B A}{ }^{+}$guests. This result is most likely because the larger cavity size of the BMP25C8 is more complementary to the bulkier BIPY ${ }^{2+}$ guests than the smaller DBA ${ }^{+}$guests, whereas the smaller crown ethers, DB24C8 and DP24C8, stabilize the smaller $\mathbf{D B A}^{+}$guests more than the larger BIPY $^{2+}$ guests. For binding between DP24C8 and DB24C8 with $\mathbf{D B A}^{+}$thread components, the binding increases with the increasing electron-withdrawing ability of the substituent, ${ }^{[9 b]}$ thus for both crowns binding is strongest with 2$\mathbf{H} \cdot \mathbf{P F}_{6}$ and weakest with $\mathbf{4}-\mathbf{H} \cdot \mathbf{P F}_{6}$. As a result of weak binding between the three crowns with $\mathbf{B I P Y}^{\mathbf{2}}$ thread components, the electronic effects are subdued and thus cause no large change in the binding due to the electron-withdrawing ability of the substituent on the thread. For DP24C8 and DB24C8 crowns, this data shows that, for molecular machines composed of $\mathbf{D B A}{ }^{+}$and $\mathbf{B I P Y}^{2+}$ recognition sites, the crown will show a strong preference for the $\mathbf{D B} \mathbf{A}^{+}$recognition site as a result of the greater than an order of magnitude difference in $K_{\mathrm{a}}$ that favors the $\mathbf{D B A}^{+}$station over the $\mathbf{B I P Y}^{\mathbf{2}}$ station.
We have obtained thermodynamic parameters by the ${ }^{1} \mathrm{H}$ NMR single-point method and ITC for the binding of the three crown ethers with $6 \cdot 2 \mathrm{PF}_{6}$ in order to compare the results from these two techniques for weakly binding systems. The general trend of the ${ }^{1} \mathrm{H}$ NMR spectra for all the 1:1 complexes formed between $\mathbf{6} \cdot 2 \mathrm{PF}_{6}$ and the crown ethers is that, at room temperature or higher, the species mostly exist as free guest and host, without any apparent association between the two that can be demonstrated by ${ }^{1} \mathrm{H}$ NMR spectroscopy. Upon cooling the solution to $235 \mathrm{~K}$, the resonances for the complexed species appear as a result of the slow exchange of the species at low temperatures and also because the binding is stronger. Because of the faster equilibration between the complexed and the uncomplexed free crowns and viologen guests at room temperature, only line broadening was observed. Thus, the $K_{a}$ values were determined at lower temperature ranges (235-293 K), and the values were used to extrapolate to $K_{a}$ at room temperature using van't Hoff plots. ${ }^{[15]}$ Figure 3 shows, as an example, the ${ }^{1} \mathrm{H}$ NMR spectra of a $1: 1$ equimolar solution of DB24C8 and 6.2PF 6 , taken at 293 (trace a) and $235 \mathrm{~K}$ (trace b). As the solution is cooled, the peaks for the complex begin to grow on account of the weak interactions holding the [2]pseudorotaxane together that are less likely to break at lower temperatures as a result of a smaller disfa-

(a)
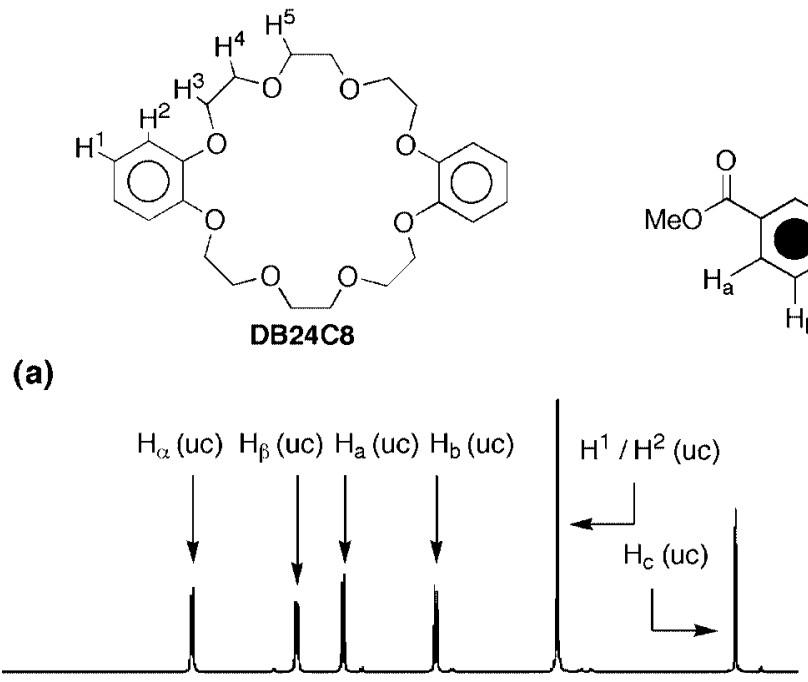<smiles>COC(=O)c1ccc(C[n+]2ccc(-c3cc[n+]([CH]C(c4ccc(F)cc4)c4ccc(C(=O)OC)c(C)c4C)c(C)c3C)cc2)cc1</smiles>

(b)
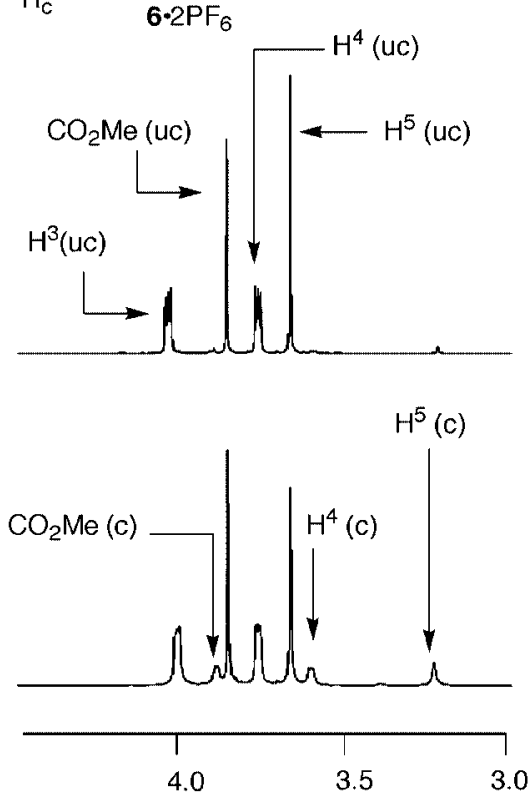

Figure 3. Partial ${ }^{1} \mathrm{H}$ NMR spectra $\left(500 \mathrm{MHz}, \mathrm{CD}_{3} \mathrm{CN}, 5 \mathrm{mM}\right)$ of $1: 1$ equimolar mixture of DB24C8 and $\mathbf{6} \cdot 2 \mathrm{PF}_{6}$ recorded at (a) 293 and (b) $235 \mathrm{~K}$, demonstrating that more complex (c) is present a lower temperatures and at higher temperatures the solution exists primarily in the uncomplexed (uc) state. 
vorable entropic contribution to the binding. Because the peaks for the complexed and uncomplexed species do not shift with changes in temperature, and because the sharp peaks in the spectrum indicate that the complexed and uncomplexed species are slow to exchange as a consequence of the slow kinetics at low temperatures, this sample is a suitable one from which to obtain a single-point binding constant.

The thermodynamic values, $\Delta H^{\circ}, \Delta S^{\circ}, \Delta G^{\circ}$, and $K_{a}$, for the binding of $6 \cdot 2 \mathrm{PF}_{6}$ with the three crown ethers DB24C8, BMP25C8, and DP24C8 were determined using both ITC and the ${ }^{1} \mathrm{H}$ NMR single-point method (Table 2). The values for $\Delta H^{\circ}$ and $\Delta S^{\circ}$ overlap within the range of the errors, and with such small $K_{\mathrm{a}}$ values, the differences are insignificant, thus showing that thermodynamic parameters obtained by ITC are comparable ${ }^{[18]}$ to those obtained by the singlepoint method, which has been extensively used to determine the thermodynamic parameters for mono and dications with various crown ethers. ${ }^{[5-9]}$ This comparison established that ITC can yield $K_{\mathrm{a}}$ values that are in agreement with those obtained from the single-point method. The singlepoint method has limitations that ITC does not have. In the case of DP24C8 $\subset 6 \cdot 2 \mathrm{PF}_{6}$, line broadening begins to occur at $250 \mathrm{~K}$ because the rate of exchange increases between the complexed and uncomplexed states. Thus, only a few data points are available for the van't Hoff plot, which leads to a poor fit when the data is extrapolated to $298 \mathrm{~K} \cdot{ }^{[16]}$ For reactions with low $K_{a}$ values, a combination of both ITC and single-point measurements could be used to describe the system accurately. Both techniques have error limits that are high compared to the $K_{\mathrm{a}}$ values for the binding of $6 \cdot 2 \mathrm{PF}_{6}$ with the crown ethers. We have shown that, on the average, the binding constants, $K_{a}$, for these 1:1 complexes with BIPY $^{2+}$ is one order of magnitude less than the $K_{a}$ values obtained for DB24C8 and DP24C8 with $\mathbf{D B A}^{+}$ thread components. However, in the case of BMP25C8 for

Table 2. A comparison of thermodynamic parameters at $298 \mathrm{~K}$ for the binding of $6 \cdot 2 \mathrm{PF}_{6}$ with the crown ethers DB24C8, DP24C8 and BMP25C8 by the single-point method ( ${ }^{1} \mathrm{H}$ NMR spectroscopy) and isothermal titration calorimetry (ITC).

\begin{tabular}{|c|c|c|c|c|}
\hline & $\begin{array}{l}K_{\mathrm{a}} \\
{\left[\mathrm{M}^{-1}\right]}\end{array}$ & 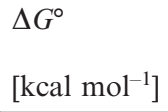 & $\begin{array}{l}\Delta H^{\circ} \\
{\left[\mathrm{kcal} \mathrm{mol}^{-1}\right]}\end{array}$ & $\begin{array}{l}\Delta S^{\circ} \\
{[\mathrm{cal}} \\
\left.\mathrm{mol}^{-1} \mathrm{~K}^{-1}\right]\end{array}$ \\
\hline Crown & \multicolumn{4}{|l|}{ ITC } \\
\hline DB24C8 & $71 \pm 29$ & -2.7 & $-3.8 \pm 1.9$ & $-4.4 \pm 5.9$ \\
\hline DP24C8 & $89 \pm 19$ & -2.8 & $-5.3 \pm 0.2$ & $-9.0 \pm 3.1$ \\
\hline \multirow[t]{2}{*}{ BMP25C8 } & $69 \pm 8$ & -2.4 & $-5.1 \pm 0.1$ & $-8.8 \pm 0.5$ \\
\hline & \multicolumn{4}{|c|}{${ }^{1} \mathrm{H}$ NMR spectroscopy } \\
\hline DB24C8 & 24 & $-1.9^{[\mathrm{a}]}$ & $-4.2^{[\mathrm{b}]}$ & $-7.9^{[\mathrm{c}]}$ \\
\hline DP24C8 & 64 & $-2.5^{[\mathrm{a}]}$ & $-3.9^{[\mathrm{b}]}$ & $-4.9^{[\mathrm{c}]}$ \\
\hline BMP25C8 & $17^{[\mathrm{d}]}$ & $-1.7^{[\mathrm{a}]}$ & $-4.9^{[\mathrm{b}]}$ & $-9.4^{[\mathrm{c}]}$ \\
\hline
\end{tabular}

[a] Free energy values were assumed to be accurate to $\pm 0.2 \mathrm{kcal}$ mol $^{-1}$, see ref. ${ }^{[19]}$. [b] Enthalpy values were obtained by neglecting the heat capacity $-\Delta C_{\mathrm{p}}^{\circ}$, see ref. ${ }^{[19]}$. [c] Entropy values were obtained by neglecting the heat capacity, see ref. ${ }^{[19]}$. [d] The binding constant could not be accurately measured as a consequence of peak broadening at low temperatures, see supporting information; for supp. inf. see also the footnote on the first page of this article. both recognition sites $\left(\mathbf{D B A}^{+}\right.$and $\mathbf{B I P Y}{ }^{2+}$ ), the binding constants have very similar and small values because the electronic effects of the substituents on binding are subdued.

\section{Rotaxane Formation}

Having shown that the viologens $5-8 \cdot 2 \mathrm{PF}_{6}$ form threaded complexes with the crown ethers DB24C8, DP24C8, and $\mathbf{B M P 2 5 C 8}$, we used the viologen derivative, $\mathbf{9} \cdot 2 \mathrm{PF}_{6}$ to template the synthesis of [2]rotaxanes with these crowns. The viologen-based [2] rotaxanes, $\mathbf{1 1} \cdot 4 \mathrm{PF}_{6}, \mathbf{1 2} \cdot 4 \mathrm{PF}_{6}$, and $13 \cdot 4 \mathrm{PF}_{6}$ were synthesized using a template-directed approach (Scheme 2) in 26, 21, and 7\% yield, respectively. The [2]rotaxanes were first assembled between the dibromide $9 \cdot 2 \mathrm{PF}_{6}$ (1 equiv.) and the selected crown ether (1.52.0 equiv.) in $\mathrm{MeNO}_{2}$. These [2]pseudorotaxanes were treated with triphenylphosphane (2.2 equiv.) overnight at room temperature. The resulting white precipitates, which were the dumbbell components $\left(\mathbf{1 0} \cdot 4 \mathrm{PF}_{6}\right)$, were collected by filtration. $\mathrm{Et}_{2} \mathrm{O}$ was added to the filtrates and the resulting precipitates were collected, subjected to anion exchange with saturated $\mathrm{NH}_{4} \mathrm{PF}_{6}$ aqueous solutions, and purified by column chromatography to yield the corresponding [2] rotaxane, which, along with the dumbbell component $10 \cdot 4 \mathrm{PF}_{6}$, were characterized by mass spectrometry, ${ }^{1} \mathrm{H}$ and ${ }^{13} \mathrm{C}$ NMR spectroscopy and $\mathrm{X}$-ray crystallography in the solid state in the case of $12 \cdot \mathrm{PF}_{6}$.

The formation of the mechanically interlocked [2] rotaxanes was confirmed by high-resolution electrospray ionization (HR-ESI) mass spectrometry. In general, for all three interlocked molecules 11-13.4PF 6 , two signifcant $\mathrm{m} / z$ peaks were observed - one corresponding to $\left[\mathrm{M}-\mathrm{PF}_{6}\right]^{+}$and the other one to $\left[\mathrm{M}-2 \mathrm{PF}_{6}\right]^{2+}$ ions, with the isotopic distribution corresponding to the $\left[\mathrm{M}-2 \mathrm{PF}_{6}\right]^{2+}$ ion of $11 \cdot 4 \mathrm{PF}_{6}$ shown in Figure 4.

In order to show that an interlocked structure has been formed, the ${ }^{1} \mathrm{H}$ NMR spectra (in $\mathrm{CD}_{3} \mathrm{CN}$ ) of the [2] rotaxane 11-13.4PF 6 can be compared with that of its components, the dumbbell-shaped component $10 \cdot 4 \mathrm{PF}_{6}$ and the corresponding free crown ether. The general trend of the proton resonances in the crown ethers and $10 \cdot 4 \mathrm{PF}_{6}$ on forming [2]rotaxanes is the upfield shift of the crown ether protons compared to those in the free crown ethers, and a significant shift in the bipyridinium protons. As an example, Figure 5 shows the ${ }^{1} \mathrm{H}$ NMR spectrum of DB24C8-based [2]rotaxane 11.4PF $\mathrm{PF}_{6}$ along with the free $\mathbf{D B 2 4 C 8}$ and the free dumbbell component $\mathbf{1 0} \cdot 4 \mathrm{PF}_{6}$.

Further confirmation of the interlocked structure was obtained from single-crystal X-ray analysis. Slow evaporation of a $\mathrm{CH}_{2} \mathrm{Cl}_{2} / \mathrm{EtOH}$ solution of the BMP25C8-based [2] rotaxane $\mathbf{1 2} \cdot 4 \mathrm{PF}_{6}$ yielded single crystals suitable for $\mathrm{X}$ ray structural analysis. The solid-state structure (Figure 6) reveals threading of the $\mathbf{B I P Y}{ }^{2+}$ unit through the center of the BMP25C8 macrocycle. The binding is stabilized mainly by $[\mathrm{C}-\mathrm{H} \cdots \mathrm{O}]$ hydrogen bonding interactions $(2.38 \AA$, $168.4^{\circ}$ ). The macrocycle adopts a Z-shaped conformation 


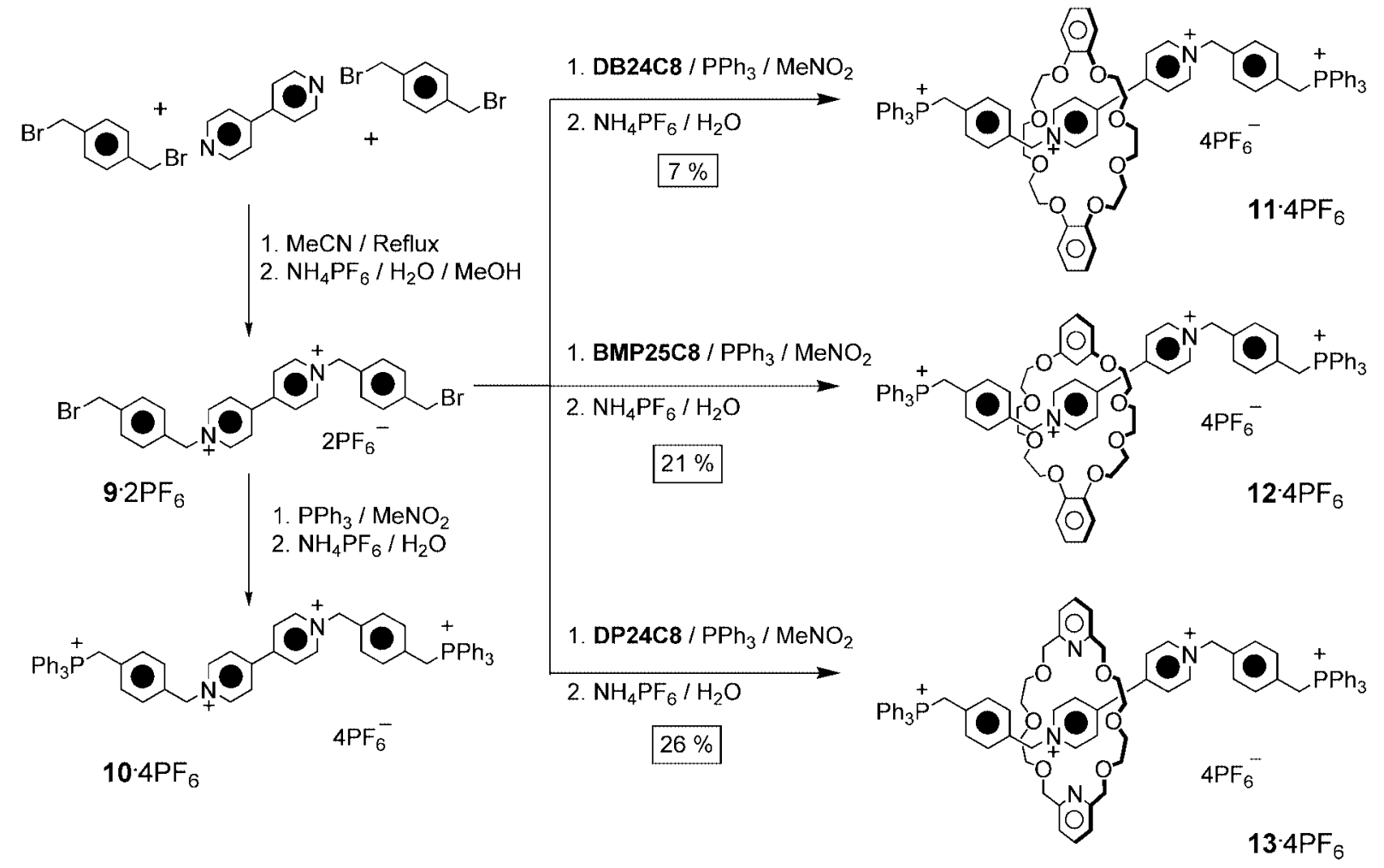

Scheme 2. Synthesis of [2]rotaxanes, $\mathbf{1 1} \cdot 4 \mathrm{PF}_{6}, \mathbf{1 2} \cdot 4 \mathrm{PF}_{6}, \mathbf{1 3} \cdot 4 \mathrm{PF}_{6}$ stoppered with triphenylphosphonium groups.

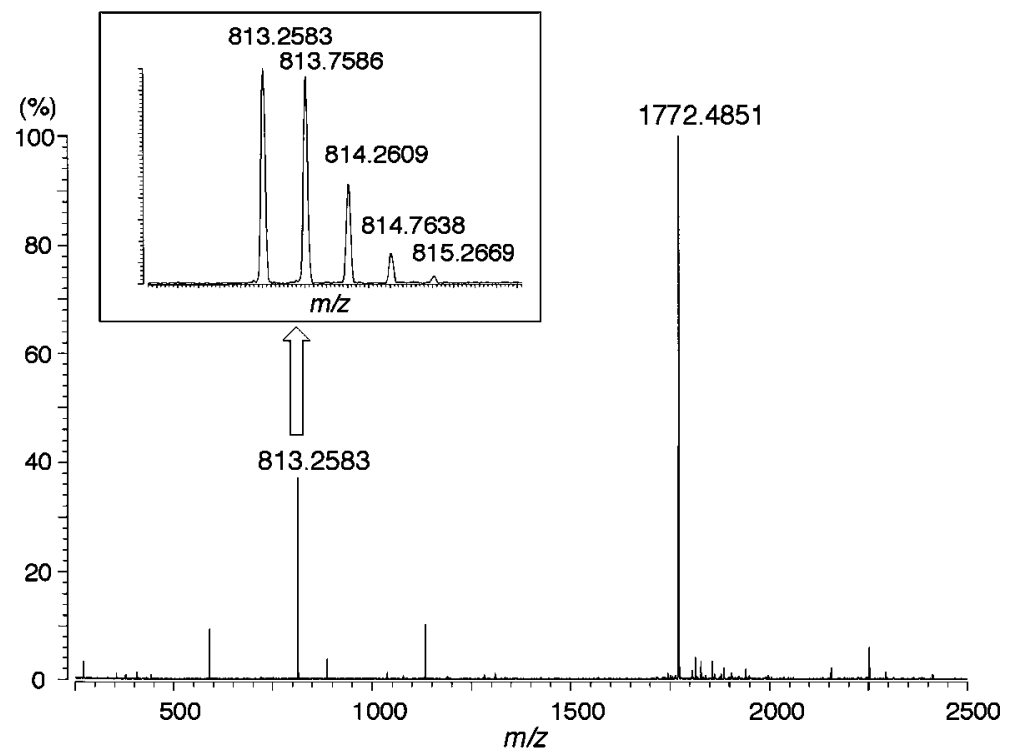

Figure 4. HR-ESI Mass spectrum of $\mathbf{D B 2 4 C 8}$-based [2] rotaxane 11.4PF $\mathrm{PF}_{6}$ The peak at $\mathrm{m} / \mathrm{z}=1772.4851$ corresponds to $\left[\mathrm{M}_{-}-\mathrm{PF}_{6}\right]^{+}$and the peak at 813.2583 corresponds to $\left[\mathrm{M}-2 \mathrm{PF}_{6}\right]^{2+}$.

around the dumbbell, where the two benzene rings face each other. However, the rings of the macrocycle do not show appreciable $[\pi \cdots \pi]$ stacking interactions with the pyridyl rings of the BIPY $^{2+}$ unit. Instead, we observe an appreciable $[\mathrm{C}-\mathrm{H} \cdots \pi]$ interaction between the proton at the 2 position of the resorcinol ring of the macrocycle and the pyridyl rings of the $\mathbf{B I P Y}^{2+}$ unit. The solid state of $\mathbf{1 2} \cdot 4 \mathrm{PF}_{6}$ is also stabilized by intramolecular $[\mathrm{C}-\mathrm{H} \cdots \pi]$ stacking interactions between the phenyl rings of the triphenylphosphonium groups of the thread and the catechol (X1) and resorcinol (X2) rings of the crown with a distance of about $4.14 \AA$. 


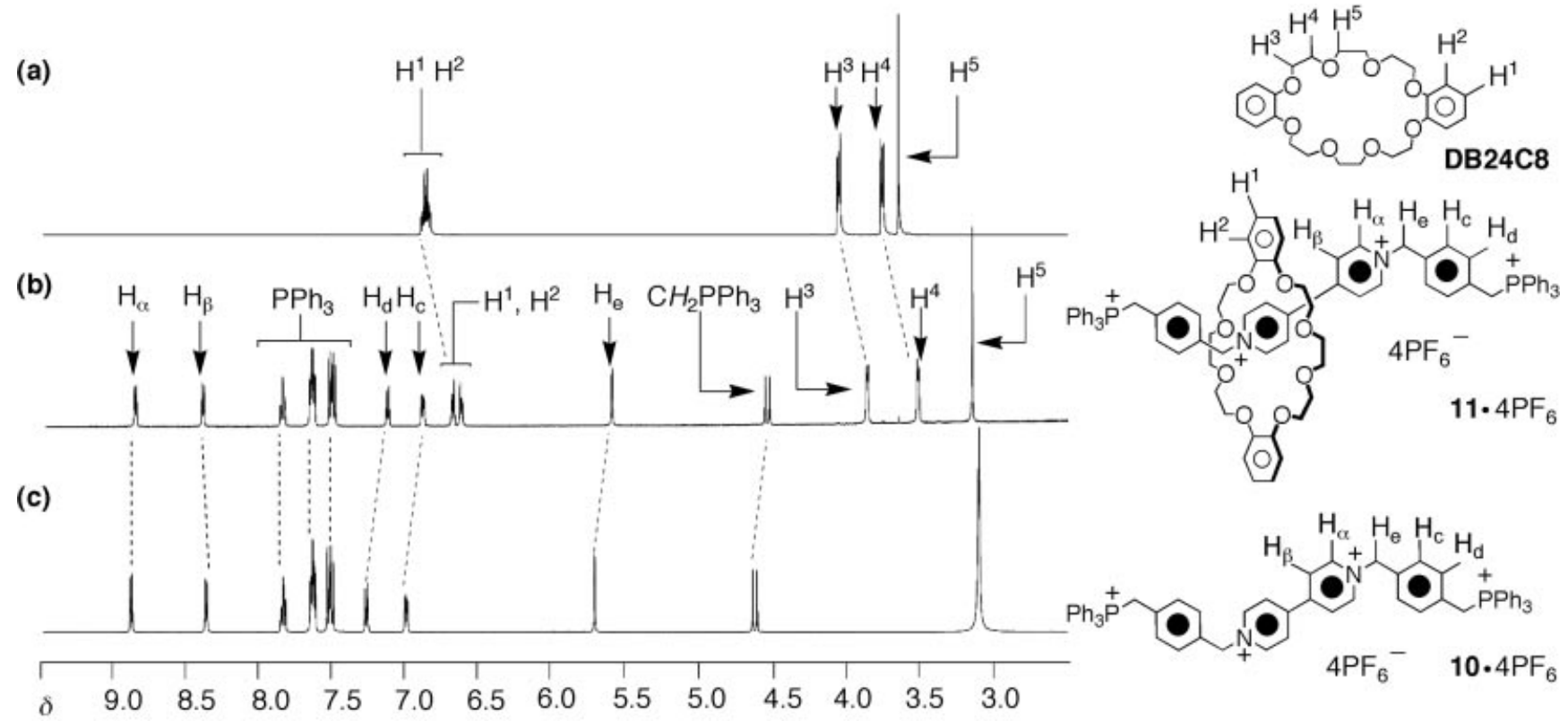

Figure 5. ${ }^{1} \mathrm{H}$ NMR spectra $\left(500 \mathrm{MHz}, \mathrm{CD}_{3} \mathrm{CN}, 10 \mathrm{~mm}, 298 \mathrm{~K}\right.$ ) of (a) free crown DB24C8, (b) [2]rotaxane 11.4PF , and (c) free dumbbell $10 \cdot 4 \mathrm{PF}_{6}$.

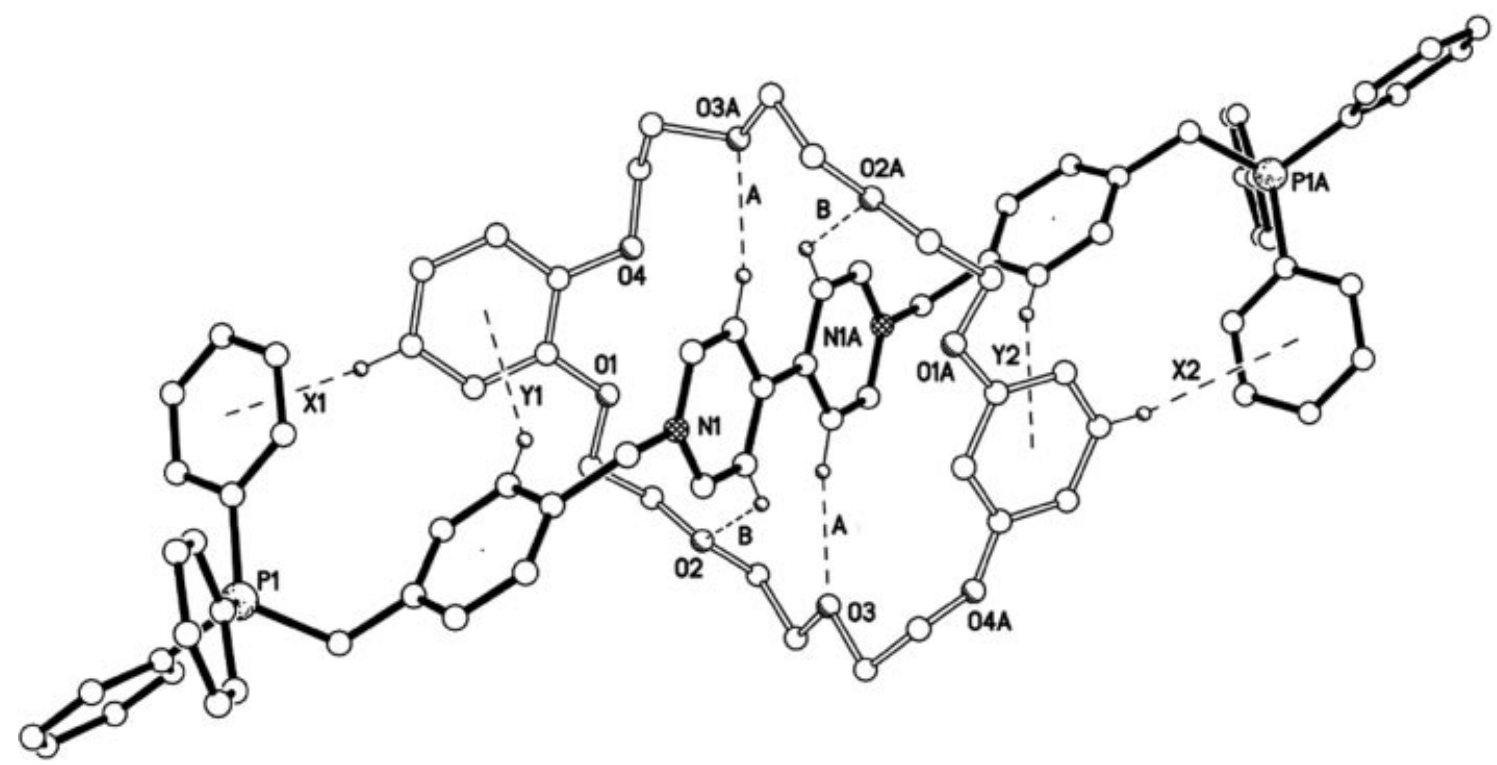

Figure 6. Molecular structure of the cationic [2] rotaxane $\mathbf{1 2} \cdot 4 \mathrm{PF}_{6}$ showing the noncovalent bonding interactions. The hydrogen-bond geometries, $[\mathrm{H} \cdots \mathrm{O}][\AA]],[\mathrm{C}-\mathrm{H} \cdots \mathrm{O}]\left[^{\circ}\right]$ are (A) 2.38, 168; (B) 2.72, 129. The $[\mathrm{C}-\mathrm{H} \cdots \pi]$ geometries, $\mathrm{H} \cdots \pi[\AA], \mathrm{C}-\mathrm{H} \cdots \pi\left[{ }^{\circ}\right]$ are $(\mathrm{X} 1) 3.14,138$; (X2) 3.72, 172, (Y1) 3.19, 150; (Y2) 3.38, 164.

\section{Conclusions}

${ }^{1} \mathrm{H}$ NMR spectroscopy, isothermal titration calorimetry (ITC) and X-ray crystallography all support the conclusion that $\mathbf{B I P Y}^{2+}$ bis(hexafluorophosphate) salts, e.g., 5-8·2PF , as well as $\mathbf{D B A}^{+}$hexafluorophosphate salts, e.g., $\mathbf{1}-\mathbf{4} \cdot \mathbf{P F}_{6}$, all form 1:1 complexes that are [2]pseudorotaxanes with the crown ethers DB24C8, DP24C8 and BMP25C8 in MeCN.
The thermodynamic parameters $\left(K_{\mathrm{a}}, \Delta G^{\circ}, \Delta H^{\circ}, \Delta S^{\circ}\right)$, which were obtained by both ITC and the ${ }^{1} \mathrm{H}$ NMR spectroscopic single-point method in $\mathrm{CD}_{3} \mathrm{CN}$ for all these [2]pseudorotaxanes, were in good agreement for any particular 1:1 complex. When complexation is weak - as with all the complexes involving the BIPY ${ }^{2+}$ salts, and with those complexes between the $\mathbf{D B A}^{+}$salts and BMP25C8 - ITC is capable of distinguishing the subtle effects involving electron- 
accepting and donating substituents on the para positions of the terminal benzyl groups on both the $\mathbf{B I P Y}^{2+}$ dications and $\mathbf{D B A}^{+}$cations. The $K_{\mathrm{a}}$ values obtained for the complexation of DB24C8 and DP24C8 with the BIPY ${ }^{2+}$ bis(hexafluorophosphate) salts $\mathbf{5}-\mathbf{8} \cdot 2 \mathrm{PF}_{6}$ are an order of magnitude less than the binding constants for the 1:1 complexes formed between these two crown ethers and the $\mathbf{D B A}^{+}$ hexafluorophosphate salts $\mathbf{1}-\mathbf{4} \cdot \mathrm{PF}_{6}$. In the case of BMP25C8, however, the $K_{\mathrm{a}}$ values with both the BIPY $2 \mathrm{PF}_{6}$ and $\mathrm{DBA} \cdot \mathrm{PF}_{6}$ salts are low, but, this time, the former are just slightly stronger than the latter. So what does all this information add up to when it comes to the template-directed synthesis of [2] rotaxanes where the dumbbell component contains a $\mathbf{B I P Y}{ }^{2+}$ unit as a template and ultimately a recognition site? The answer is that it becomes just as likely that any one of the three crown ethers DB24C8, DP24C8 or BMP25C8 - could serve as the ring component, but that the yield of the rotaxane is not going to be all that high as a result of the weak interactions between the thread and the crown. And what about the design and construction of $\mathrm{pH}$-controllable switches based on bistable [2] rotaxanes containing both dialkylammonium and bipyridinium recognition sites in their dumbbell components? The answer is that the best bistable [2] rotaxanes incorporating these recognition sites are going to involve ester functions in their dumbbell components and will employ DP24C8 or, failing that, DB24C8 as the ring component.

\section{Experimental Section}

General Methods: All reagents were purchased from commercial suppliers and used as received. Dibenzyl-4,4'-bipyridinium bis(hexafluorophosphate $)^{[12]}\left(\mathbf{5} \cdot 2 \mathrm{PF}_{6}\right)$, bis $\left(4^{\prime \prime}\right.$-methylbenzyl)-4,4'-bipyridinium bis(hexafluorophosphate) $\left(\mathbf{8} \cdot 2 \mathrm{PF}_{6}\right),{ }^{[13]}$ bis $\left(4^{\prime \prime}\right.$-bromomethylbenzyl)-4,4'-bipyridinium bis(hexafluorophosphate) $\left(\mathbf{9} \cdot 2 \mathrm{PF}_{6}\right)^{[14]}$ benzometaphenylene[25]crown-8 (BMP25C8) ${ }^{[9 e]}$ and dipyrido[24]crown-8 (DP24C8) ${ }^{[9 \mathrm{e}]}$ were prepared according to published literature procedures and DB24C8 was purchased from a commercial supplier. Solvents were dried according to literature procedures. Thin-layer chromatography was carried out using aluminum sheets precoated with silica gel 60F (Merck 5554). Column chromatography was performed on silica gel 60 (Merck 40-60 $\mu \mathrm{m}, 230-400$ mesh). Melting points are uncorrected. ${ }^{1} \mathrm{H}$ and ${ }^{13} \mathrm{C}$ NMR spectroscopy and fast atom bombardment (FAB), high-resolution matrix-assisted laser-desorption ionization (HR-MALDI) and highresolution electrospray ionization (HR-ESI) mass spectrometry (MS) were all obtained with commercially available instrumentation. NMR Spectra were recorded in $\mathrm{CD}_{3} \mathrm{CN}$ solution with the residual solvent peaks used as internal standards. FAB-MS were obtained with a spectrometer equipped with a krypton primary atom beam using a 3-nitrobenzyl alcohol matrix.

6.2PF : Methyl 4-bromomethylbenzoate $(1.5 \mathrm{~g}, 6.5 \mathrm{mmol})$ was added to a refluxing solution of $4,4^{\prime}$-bipyridine $(500 \mathrm{mg}$, $3.2 \mathrm{mmol})$, dissolved in $\mathrm{MeCN}(100 \mathrm{~mL})$. The reaction mixture turned yellow upon the addition of methyl 4-(bromomethyl)benzoate and a yellow precipitate started to form. The reaction mixture was heated under reflux for $3 \mathrm{~h}$, after which time it was cooled down to room temperature. The precipitate was filtered, washed with $\mathrm{MeCN}$ and air-dried to give a yellow solid, which was subjected to anion exchange by dissolving it in hot $\mathrm{H}_{2} \mathrm{O}$ and adding saturated aqueous $\mathrm{NH}_{4} \mathrm{PF}_{6}$ until no further precipitation was observed. The resulting solid was filtered, washed with $\mathrm{H}_{2} \mathrm{O}$ and dried to yield $6 \cdot 2 \mathrm{PF}_{6}$ as a white solid $(2.2 \mathrm{~g}, 93 \%)$; m.p. $230-233{ }^{\circ} \mathrm{C}$ (dec.). ${ }^{1} \mathrm{H}$ NMR (500 MHz, $\left.\mathrm{CD}_{3} \mathrm{CN}\right): \delta=3.87$ (s, $\left.6 \mathrm{H}\right), 5.86$ (s, 4 H), $7.57(\mathrm{~d}, J=8.3 \mathrm{~Hz}, 4 \mathrm{H}), 8.08(\mathrm{~d}, J=8.3 \mathrm{~Hz}, 4 \mathrm{H}), 8.36(\mathrm{~d}, J=$ $6.9 \mathrm{~Hz}, 4 \mathrm{H}), 8.94$ (d, $J=6.9 \mathrm{~Hz}, 4 \mathrm{H}) \mathrm{ppm} .{ }^{13} \mathrm{C} \mathrm{NMR}(125 \mathrm{MHz}$, $\left.\mathrm{CD}_{3} \mathrm{CN}\right): \delta=165.8,150.3,145.7,137.0,131.6,130.5,129.3,127.5$, 63.9, 51.9 ppm. HR-ESI-MS: $m / z(\%)=599.1533$ (100) (calculated $\left[\mathrm{M}-\mathrm{PF}_{6}\right]^{+}$requires 599.1529). Slow evaporation of a solution of 6. $2 \mathrm{PF}_{6}$ in $\mathrm{MeCN} / i \mathrm{Pr}_{2} \mathrm{O}$ yielded single crystals of the [2]pseudorotaxane suitable for X-ray crystallography (see Supporting Information).

7.2PF $\mathbf{2}$ : 4-Fluorobenzyl bromide $(1.27 \mathrm{~g}, 6.7 \mathrm{mmol})$ was added to a MeCN solution $(100 \mathrm{~mL}$ ) of 4,4'-bipyridine (500 mg, $3.2 \mathrm{mmol}$ ), heated under reflux. The reaction mixture turned yellow upon the addition of 4-fluorobenzyl bromide and a yellow precipitate started to form. The reaction mixture was heated under reflux for $3 \mathrm{~h}$, after which time it was cooled down to room temperature. The precipitate was filtered, washed with $\mathrm{MeCN}$ and air-dried to give a yellow solid, which was subjected to anion exchange by dissolving it in hot $\mathrm{H}_{2} \mathrm{O}$ and adding saturated aqueous $\mathrm{NH}_{4} \mathrm{PF}_{6}$ until no further precipitation was observed. The resulting solid was filtered, washed with $\mathrm{H}_{2} \mathrm{O}$ and dried to yield $7 \cdot 2 \mathrm{PF}_{6}$ as a white solid (1.95 g, 92\%); m.p. $230-233{ }^{\circ} \mathrm{C}$ (dec.). ${ }^{1} \mathrm{H} \mathrm{NMR}\left(500 \mathrm{MHz}, \mathrm{CD}_{3} \mathrm{CN}\right): \delta=8.95(\mathrm{~d}$, $J=7.6 \mathrm{~Hz}, 4 \mathrm{H}), 8.37(\mathrm{~d}, J=7.6 \mathrm{~Hz}, 4 \mathrm{H}), 7.57(\mathrm{~m}, 4 \mathrm{H}), 7.27(\mathrm{~m}$, $4 \mathrm{H}), 5.81$ (s, $4 \mathrm{H}) \mathrm{ppm} .{ }^{13} \mathrm{C} \mathrm{NMR}\left(125 \mathrm{MHz}, \mathrm{CD}_{3} \mathrm{CN}\right): \delta=150.22$, $145.39,131.85,131.78,127.35,116.42,116.24,63.79 \mathrm{ppm} .{ }^{19} \mathrm{~F}$ NMR (400 MHz, $\left.\mathrm{CD}_{3} \mathrm{CN}\right): \delta=-72.31(\mathrm{~d}, J=45 \mathrm{~Hz}),-113.08$ ppm. HR-ESI-MS: $m / z(\%)=519.1233(100)\left(\right.$ calculated $\left[\mathrm{M}-\mathrm{PF}_{6}\right]^{+}$ requires 519.12136).

Pseudorotaxane Self-Assembly: Solutions of DB24C8, BMP25C8, DP24C8 and $6 \cdot 2 \mathrm{PF}_{6}(10 \mathrm{~mm}$ each), were prepared by dissolving each component separately in $\mathrm{CD}_{3} \mathrm{CN}(0.600 \mathrm{~mL})$ in individual NMR tubes. The [2]pseudorotaxanes are formed by mixing an equimolar amount of crown ether and a substrate in a new NMR tube. The tubes were inverted several times to ensure efficient mixing. ${ }^{1} \mathrm{H}$ NMR spectra were recorded 5 min after the mixing. Slow evaporation of a solution of the 1:1 complex between DP24C8 and 6. $2 \mathrm{PF}_{6}$ in $\mathrm{MeCN} / i \mathrm{Pr}_{2} \mathrm{O}$ yielded single crystals suitable for X-ray crystallography.

10.4PF $\mathbf{P}: \mathrm{Ph}_{3} \mathrm{P}(350 \mathrm{mg}, 1.32 \mathrm{mmol})$ was added to a solution of 9. $2 \mathrm{PF}_{6}(500 \mathrm{mg}, 0.60 \mathrm{mmol})$ dissolved in $\mathrm{MeNO}_{2}(70 \mathrm{~mL})$. The reaction was left to stir overnight at room temperature. The resulting white precipitate was filtered, washed with $\mathrm{CH}_{2} \mathrm{Cl}_{2}$ and collected. The air-dried precipitate was dissolved in $\mathrm{H}_{2} \mathrm{O}$ and a saturated aqueous solution of $\mathrm{NH}_{4} \mathrm{PF}_{6}$ was added until no further precipitated was observed. The resulting solid was filtered, washed with $\mathrm{H}_{2} \mathrm{O}$ and dried to yield $\mathbf{1 0} \cdot 4 \mathrm{PF}_{6}(0.6 \mathrm{~g}, 76 \%)$; m.p. $196-198^{\circ} \mathrm{C}$ (dec.). ${ }^{1} \mathrm{H}$ NMR (500 MHz, $\left.\mathrm{CD}_{3} \mathrm{CN}\right): \delta=4.66(\mathrm{~d}, J=14.8 \mathrm{~Hz}, 4$ H), $5.74(\mathrm{~s}, 4 \mathrm{H}), 7.01(\mathrm{~d}, J=8.0 \mathrm{~Hz}, 4 \mathrm{H}), 7.03(\mathrm{~d}, J=8.0 \mathrm{~Hz}, 4$ $\mathrm{H}), 7.52-7.54(\mathrm{~m}, 12 \mathrm{H}), 7.64-7.83(\mathrm{~m}, 12 \mathrm{H}), 7.86-7.91(\mathrm{~m}, 6 \mathrm{H})$, $8.37(\mathrm{~d}, J=6.9 \mathrm{~Hz}, 4 \mathrm{H}), 8.88(\mathrm{~d}, J=6.9 \mathrm{~Hz}, 4 \mathrm{H}) \mathrm{ppm} .{ }^{13} \mathrm{C} \mathrm{NMR}$ (125 MHz, $\mathrm{CD}_{3} \mathrm{CN}$ ): $\delta=150.4,145.6,135.5,134.1,133.4,133.2$, $131.9,131.8,130.3,130.1,129.9,129.8,129.5,129.4,129.1,127.5$, 63.9, $29.1 \mathrm{ppm}$. MS (FAB): $m / z(\%)=1324.10(25), 1178.34(83)$, $1033.38(100)\left(\left[\mathrm{M}-\mathrm{PF}_{6}\right]^{+},\left[\mathrm{M}-2 \mathrm{PF}_{6}\right]^{+},\left[\mathrm{M}-3 \mathrm{PF}_{6}\right]^{+}\right.$require $1324.22,1178.23,1033.23)$.

General Procedure for the Synthesis of [2]Rotaxanes, $11 \cdot 4 \mathrm{PF}_{6}$, 12.4PF $\mathrm{PF}_{\mathbf{6}}, \mathbf{1 3} \cdot \mathbf{4} \mathrm{PF}_{\mathbf{6}}: \mathrm{Ph}_{3} \mathrm{P}$ (2.2 equiv.) was added to a solution of 9. $2 \mathrm{PF}_{6}$ (1 equiv.) and crown (1.5-2.0 equiv.) dissolved in $\mathrm{MeNO}_{2}$. The reaction mixture was left to stir overnight at room temperature. The resulting white precipitate was filtered off, washed with 
$\mathrm{CH}_{2} \mathrm{Cl}_{2}$ and collected. Characterization of the crystalline powder demonstrated it to be the dumbbell compound $\mathbf{1 0} \cdot 4 \mathrm{PF}_{6} \cdot \mathrm{Et}_{2} \mathrm{O}$ was then added to the filtrate and the resulting precipitate was filtered and washed with $\mathrm{Et}_{2} \mathrm{O}$. The air-dried precipitate was dissolved in $\mathrm{H}_{2} \mathrm{O}$ and a saturated aqueous solution of $\mathrm{NH}_{4} \mathrm{PF}_{6}$ was added until no further precipitated was observed. The resulting solid was filtered, washed with $\mathrm{H}_{2} \mathrm{O}$ and dried. The crude compound was purified by column chromatography $\left[\mathrm{SiO}_{2}\right.$ : $\mathrm{MeOH} / \mathrm{CH}_{2} \mathrm{Cl}_{2}, 9: 1$, followed by $\left.\mathrm{MeOH} / \mathrm{NH}_{4} \mathrm{Cl}(2 \mathrm{M}) / \mathrm{MeNO}_{2}, 7: 2: 1\right]$ to give the appropriate [2]rotaxane.

11.4PF : $_{6}$ : Reacting $\mathrm{Ph}_{3} \mathrm{P}(64.3 \mathrm{mg}, 0.25 \mathrm{mmol})$ and the dibromide 9.2PF 6 (90.3 mg, $0.11 \mathrm{mmol})$, in the presence of DB24C8 (100 mg, $0.22 \mathrm{mmol})$ in $\mathrm{MeNO}_{2}(15 \mathrm{~mL})$ afforded after work-up as described above, $\mathbf{1 1} \cdot 4 \mathrm{PF}_{6}$ as pale yellow solid (15 mg, 7\%); m.p. $232-235^{\circ} \mathrm{C}$ (dec.). ${ }^{1} \mathrm{H}$ NMR $\left(500 \mathrm{MHz}, \mathrm{CD}_{3} \mathrm{CN}\right): \delta=3.17$ (s, $\left.8 \mathrm{H}\right), 3.53-3.54$ $(\mathrm{m}, 8 \mathrm{H}), 3.88-3.89(\mathrm{~m}, 8 \mathrm{H}), 4.58(\mathrm{~d}, J=14.9 \mathrm{~Hz}, 4 \mathrm{H}), 5.62(\mathrm{~s}, 4$ $\mathrm{H}), 6.65-6.66(\mathrm{~m}, 4 \mathrm{H}), 6.70-6.71(\mathrm{~m}, 4 \mathrm{H}), 6.93(\mathrm{~d}, J=8.0 \mathrm{~Hz}, 4$ $\mathrm{H}), 7.16(\mathrm{~d}, J=8.0 \mathrm{~Hz}, 4 \mathrm{H}), 7.51-7.55(\mathrm{~m}, 12 \mathrm{H}), 7.65-7.68(\mathrm{~m}$, $12 \mathrm{H}), 7.86-7.90(\mathrm{~m}, 6 \mathrm{H}), 8.43(\mathrm{~d}, J=6.8 \mathrm{~Hz}, 4 \mathrm{H}), 8.88(\mathrm{~d}, J=$ $6.8 \mathrm{~Hz}, 4 \mathrm{H}) \mathrm{ppm} .{ }^{13} \mathrm{C} \mathrm{NMR}\left(125 \mathrm{MHz}, \mathrm{CD}_{3} \mathrm{CN}\right): \delta=146.8,144.8$, $135.3,135.2,134.1,134.0,131.4,131.3,130.1,130.0,129.6,129.5$, $127.1,120.9,111.7,70.4,70.3,69.5,67.8,63.2,28.5$ ppm. MS $\left(\right.$ HR-ESI) $m / z(\%)=1772.4851(100), 813.2583(40)\left(\left[\mathrm{M}-\mathrm{PF}_{6}\right]^{+}\right.$, $\left[\mathrm{M}-2 \mathrm{PF}_{6}\right]^{+}$require $\left.1772.4813,813.2566\right)$.

12.4PF $\mathbf{P F}_{\mathbf{6}}$ : The reaction of $\mathrm{Ph}_{3} \mathrm{P}(42.9 \mathrm{mg}, 0.16 \mathrm{mmol})$ with the dibromide $9 \cdot 2 \mathrm{PF}_{6}(60.2 \mathrm{mg}, \quad 0.074 \mathrm{mmol})$ in the presence of BMP25C8 (50.0 mg, $0.11 \mathrm{mmol}$ ) afforded, after work-up as described above, $\mathbf{1 2} \cdot 4 \mathrm{PF}_{6}$ as a yellow solid (30 mg, $21 \%$ ); m.p. 159 $161{ }^{\circ} \mathrm{C}$ (dec.). ${ }^{1} \mathrm{H}$ NMR (500 MHz, $\mathrm{CD}_{3} \mathrm{CN}$ ): $\delta=3.66-3.67$ (m, 4 H), 3.69-3.71 (m, 4 H), 3.82 (s, 8 H), 3.86-3.87 (m, 4 H), 3.92-3.93 $(\mathrm{m}, 4 \mathrm{H}), 4.01$ (br. s, $1 \mathrm{H}), 4.69$ (d, $J=15 \mathrm{~Hz}, 4 \mathrm{H}), 5.70(\mathrm{~s}, 4 \mathrm{H})$, 5.90-5.92 (m, 2 H), 6.40-6.42 (m, 3 H), 6.56-6.58 (m, 2 H), 7.13 $(\mathrm{d}, J=6.9 \mathrm{~Hz}, 4 \mathrm{H}), 7.47(\mathrm{~d}, J=6.9 \mathrm{~Hz}, 4 \mathrm{H}), 7.51-7.55(\mathrm{~m}, 12$ $\mathrm{H}), 7.61-7.64(\mathrm{~m}, 12 \mathrm{H}), 7.76(\mathrm{~d}, J=6.8 \mathrm{~Hz}, 4 \mathrm{H}), 7.85-7.92(\mathrm{~m}$, $6 \mathrm{H}), 8.98(\mathrm{~d}, J=6.8 \mathrm{~Hz}, 4 \mathrm{H}) \mathrm{ppm} .{ }^{13} \mathrm{C} \mathrm{NMR}(125 \mathrm{MHz}$, $\left.\mathrm{CD}_{3} \mathrm{CN}\right): \delta=159.0,148.1,147.1,145.7,135.4,135.3,134.2,134.1$, $132.1,132.0,130.6,130.3,130.1,125.6,121.0,113.2,104.3,70.8$, $70.3,69.8,67.5,67.1,63.8,29.9$ ppm. MS (HR-ESI): $m / z(\%)=$ $1772.4873(50), 813.2542(100)\left(\left[\mathrm{M}-\mathrm{PF}_{6}\right]^{+},\left[\mathrm{M}-2 \mathrm{PF}_{6}\right]^{+}\right.$require 1772.4813, 813.2566). Slow evaporation of a solution of $12 \cdot 4 \mathrm{PF}_{6}$ in $\mathrm{CH}_{2} \mathrm{Cl}_{2} / \mathrm{EtOH}$ yielded single crystals suitable for X-ray crystallography.

13.4PF : The reaction $\mathrm{Ph}_{3} \mathrm{P}(45.0 \mathrm{mg}, 0.17 \mathrm{mmol})$ with the dibromide $9 \cdot 2 \mathrm{PF}_{6}(64.6 \mathrm{mg}, 0.080 \mathrm{mmol})$ in the presence of DP24C8 (50.0 $\mathrm{mg}, 0.12 \mathrm{mmol}$ ) afforded, after work-up as described above, 13. $4 \mathrm{PF}_{6}$ as a solid $(39 \mathrm{mg}, 26 \%)$; m.p. $179-181^{\circ} \mathrm{C}(\mathrm{dec}.) .{ }^{1} \mathrm{H}$ NMR (500 MHz, $\left.\mathrm{CD}_{3} \mathrm{CN}\right): \delta=3.60-3.62(\mathrm{~m}, 8 \mathrm{H}), 3.70-3.71(\mathrm{~m}, 8 \mathrm{H})$, $3.88(\mathrm{~s}, 8 \mathrm{H}), 4.75(\mathrm{~d}, J=14.9 \mathrm{~Hz}, 4 \mathrm{H}), 5.70(\mathrm{~s}, 4 \mathrm{H}), 6.73-6.80$ $(\mathrm{m}, 6 \mathrm{H}), 7.13(\mathrm{~d}, J=8.5 \mathrm{~Hz}, 4 \mathrm{H}), 7.42(\mathrm{~d}, J=8.5 \mathrm{~Hz}, 4 \mathrm{H}), 7.53$ $7.59(\mathrm{~m}, 12 \mathrm{H}), 7.63-7.68(\mathrm{~m}, 12 \mathrm{H}), 7.85-7.90(\mathrm{~m}, 6 \mathrm{H}), 8.19(\mathrm{~d}$, $J=6.9 \mathrm{~Hz}, 4 \mathrm{H}), 8.78(\mathrm{~d}, J=6.9 \mathrm{~Hz}, 4 \mathrm{H}) \mathrm{ppm} .{ }^{13} \mathrm{C} \mathrm{NMR}$ (125 MHz, $\left.\mathrm{CD}_{3} \mathrm{CN}\right): \delta=155.6,144.3,135.4,135.3,134.1,134.0$, 132.0, 131.9, 130.2, 130.1, 129.9, 129.8, 127.7, 74.1, 70.6, 70.2, 63.5, 29.4 ppm. MS (HR-ESI): $m / z(\%)=1741.5815$ (10), $798.2561(100)$ $\left(\left[\mathrm{M}-\mathrm{PF}_{6}\right]^{+},\left[\mathrm{M}-2 \mathrm{PF}_{6}\right]^{+}\right.$require $\left.1772.4813,813.2566\right)$.

X-ray Crystallography: The intensity data for the [2]pseudorotaxane DP24C8 $\subset 6 \cdot 2 \mathrm{PF}_{6}$ were collected with a Siemens P4 diffractometer, and those for the [2] rotaxane $\mathbf{1 2} \cdot 4 \mathrm{PF}_{6}$ were collected with a Bruker Smart 1000 CCD-based X-ray diffractometer. ${ }^{[20 a]}$ The frames for the latter data collection were integrated with the Bruker SAINT program system using a narrow-frame integration algorithm. ${ }^{[20 \mathrm{a}]}$ The structures were solved by direct methods and refined based on $F^{2}$ using the SHELXTL software package. ${ }^{[20 \mathrm{~b}]}$ CCDC-264706 and -264433 contain the supplementary crystallographic data for this paper. These data can be obtained free of charge from The Cambridge Crystallographic Data Centre via www.ccdc.cam.ac.uk/data_request/cif.

Crystal Data for DP24C8 $\subset$ 6.2PF $:\left[\mathrm{C}_{50} \mathrm{H}_{56} \mathrm{~N}_{4} \mathrm{O}_{10}\right]\left(\mathrm{PF}_{6}\right)_{2}, \quad M=$ 1162.93, monoclinic, $P 2_{1} / n$ (no. 14), $a=12.8321(14), b=$ 13.0828(12), $c=16.2059(13) \AA, \beta=97.211(8)^{\circ}, V=2699.1(4) \AA^{3}$, $Z=2\left(C_{i}\right.$ symmetry $), D_{\text {calcd. }}=1.431 \mathrm{~g} \mathrm{~cm}^{-3}, \mu\left(\right.$ Mo- $\left.K_{\alpha}\right)=$ $0.182 \mathrm{~mm}^{-1}, T=293 \mathrm{~K}$, colorless prisms; 3978 independent measured reflections, $F^{2}$ refinement, $R_{1}=0.076, w R_{2}=0.191,2525$ independent observed reflections $\left[\left|F_{\mathrm{o}}\right|>4 \sigma\left(\left|F_{\mathrm{o}}\right|\right), 2 \theta_{\max }=47^{\circ}\right], 378$ parameters. CCDC-264706.

Crystal Data for $\mathbf{1 2} \cdot \mathbf{4} \mathrm{PF}_{\mathbf{6}}:\left[\mathrm{C}_{86} \mathrm{H}_{86} \mathrm{~N}_{2} \mathrm{O}_{8}\right]\left[\mathrm{PF}_{6}\right]_{4}, M=1917.39$, triclinic, $P \overline{1}, a=9.9733(15), b=10.7391(17), c=20.800(3) \AA, a=$ 97.959(3), $\beta=91.794(3), \gamma=96.608(3)^{\circ}, V=2189.1(6) \AA^{3}, Z=1$, $D_{\text {calcd. }}=1.454 \mathrm{~g} \mathrm{~cm}^{-3}, \mu\left(\right.$ Mo- $\left.K_{\alpha}\right)=2.30 \mathrm{~cm}^{-1}, F(000)=986, T=$ $120 \mathrm{~K}, 0.35 \times 0.15 \times 0.10 \mathrm{~mm}$, refined based on $F^{2}$ to give $R_{1}=$ $0.0803, w R_{2}=0.2190$ for 8973 independent observed reflections $\left[\left|F_{\mathrm{o}}\right|>4 \sigma\left(\left|F_{\mathrm{o}}\right|\right), 2 \theta \leq 50^{\circ}\right]$ and 652 parameters. CCDC-264433.

Isothermal Titration Microcalorimetry: Microcalorimetry was carried out using a Microcal VP-ITC titration microcalorimeter. 3 $7 \mu \mathrm{L}$ aliquouts of degassed solutions of the guest in $\mathrm{MeCN}$ were titrated into stirring solutions of the host at $298 \mathrm{~K}$. The heat of dilution for each titration was measured by determining the heat released by the injection of guest into $\mathrm{MeCN}$ in the absence of crown, and the enthalpy of dilution was subtracted from the enthalpy of the titration to determine the enthalpy of complexation. Software provided by Microcal LLC was used to compute the thermodynamic parameters of the titration $\left(\Delta G^{\circ}, K_{\mathrm{a}}, \Delta S^{\circ}, \Delta H^{\circ}\right)$ based on the one-site binding model. The reported values in Table 1 are the mean results of multiple titration runs, and errors are reported as a standard deviation from the mean.

Supporting Information (see footnote on the first page of this article): Mass spectrometric data of pseudorotaxanes formed between the threads $\mathbf{1}-\mathbf{H}-\mathbf{4}-\mathbf{H} \cdot \mathbf{P F}_{6}$ and $\mathbf{5}-\mathbf{8} \cdot 2 \mathrm{PF}_{6}$ with the crowns DB24C8, DP24C8 and BMP25C8; ${ }^{13} \mathrm{C}$ and ${ }^{1} \mathrm{H}$ NMR spectra of the threads 1-H $-4-\mathrm{H} \cdot \mathrm{PF}_{6}$ and $5-8 \cdot 2 \mathrm{PF}_{6}$; variable temperature ${ }^{1} \mathrm{H}$ NMR complexation studies of the binding between thread $6 \cdot 2 \mathrm{PF}_{6}$ with crowns DB24C8, DP24C8 and BMP25C8; sample ITC runs (uncorrected) between threads $\mathbf{1}-\mathbf{H} \cdot \mathrm{PF}_{6}$ and $\mathbf{5} \cdot 2 \mathrm{PF}_{6}$ with crowns DB24C8, DP24C8 and BMP25C8; solid-state structural data for DP24C8 $\subset 6 \cdot 2 \mathrm{PF}_{6}$; solid-state structural data for $6 \cdot 2 \mathrm{PF}_{6}$.

\section{Acknowledgments}

The research was supported by National Science Foundation (NSF) grant (CHE 0317170) and two NSF equipment grants (CHE 9974928 and CHE 0092036), We are grateful to the National Science Foundation for financial support through a GK-12 program grant DGE 02-31988 fellowship to A.B.B.

[1] a) F. Diederich, L. Echegoyen, M. Gómez-López, R. Kessinger, J. F. Stoddart, J. Chem. Soc., Perkin Trans. 2 1999, 1577-1586; b) S. J. Cantrill, A. R. Pease, J. F. Stoddart, J. Chem. Soc., Dalton Trans. 2000, 3715-3734; c) H. W. Gibson, N. Yamaguchi, L. Hamilton, J. W. Jones, J. Am. Chem. Soc. 2002, 124, 46534665; d) S.-I. Kawano, N. Fujita, S. Shinkai, Chem. Commun. 2003, 1352-1353; e) S. J. Cantrill, R. H. Grubbs, D. Lanari, K. C.-F. Leung, A. Nelson, K. G. Poulin-Kerstien, S. P. Smidt, J. F. Stoddart, D. A. Tirrell, Org. Lett. 2005, 7, 4213-4216. 
[2] a) A. G. Kolchinski, D. H. Busch, N. W. Alcock, J. Chem. Soc., Chem. Commun. 1995, 1289-1291; b) P. T. Glink, C. Schiavo, J. F. Stoddart, D. J. Williams, Chem. Commun. 1996, 14831490; c) P. R. Ashton, P. T. Glink, J. F. Stoddart, P. A. Tasker, A. J. P. White, D. J. Williams, Chem. Eur. J. 1996, 2, 729-736; d) S.-H. Chiu, S. J. Rowan, S. J. Cantrill, J. F. Stoddart, A. J. P. White, D. J. Williams, Chem. Eur. J. 2002, 8, 5170-5183; e) H. Iwamoto, K. Itoh, H. Nagamiya, Y. Fukazawa, Tetrahedron Lett. 2003, 44, 5773-5776; f) A. F. M. Kilbinger, S. J. Cantrill, A. W. Waltman, M. W. Day, R. H. Grubbs, Angew. Chem. Int. Ed. 2003, 42, 3281-3285; g) Y. Furusho, T. Oku, T. Hasegawa, A. Tsuboi, N. Kihara, T. Takata, Chem. Eur. J. 2003, 9, 28952903; h) I. Yoon, M. Narita, T. Shimizu, M. Asakawa, J. Am. Chem. Soc. 2004, 126, 16740-16741; i) F. Aricó, T. Chang, S. J. Cantrill, S. I. Khan, J. F. Stoddart, Chem. Eur. J. 2005, 11, 4655-4666.

[3] a) V. Dvornikovs, B. E. House, M. Kaetzel, J. R. Dedman, D. B. Smithrud, J. Am. Chem. Soc. 2003, 125, 8290-8301; b) J. D. Badjić, V. Balzani, A. Credi, S. Silvi, J. F. Stoddart, Science 2004, 303, 1845-1849; c) S. Garaudee, S. Silvi, M. Venturi, A. Credi, A. H. Flood, J. F. Stoddart, ChemPhysChem 2005, 6, 2145-2152.

[4] a) P. R. Ashton, R. Ballardini, V. Balzani, I. Baxter, A. Credi, M. C. T. Fyfe, M. T. Gandolfi, M. Gómez-López, M.-V. Martínez-Díaz, A. Piersanti, N. Spencer, J. F. Stoddart, M. Venturi, A. J. P. White, D. J. Williams, J. Am. Chem. Soc. 1998, 120, 11932-11942; b) M. Montalti, L. Prodi, Chem. Commun. 1998, 1461-1462; c) A. M. Elizarov, S.-H. Chiu, J. F. Stoddart, J. Org. Chem. 2002, 67, 9175-9181; d) J. W. Jones, W. S. Bryant, A. W. Bosman, R. A. J. Janssen, E. W. Meijer, H. W. Gibson, J. Org. Chem. 2003, 68, 2385-2389; e) M. Horie, Y. Suzaki, K. Osakada, J. Am. Chem. Soc. 2004, 126, 3684-3685.

[5] a) M. Horn, J. Ihringer, P. T. Glink, J. F. Stoddart, Chem. Eur. J. 2003, 9, 4046-4054; b) J. W. Choi, A. H. Flood, D. W. Steuerman, S. Nygaard, A. B. Braunschweig, N. N. P. Moonen, B. W. Laursen, Y. Luo, E. DeIonno, A. J. Peters, J. O. Jeppesen, K. $\mathrm{Xu}$, J. F. Stoddart, J. R. Heath, Chem. Eur. J. 2006, 12, 261279; c) A. B. Braunschweig, B. N. Northrop, J. F. Stoddart, J. Mater. Chem. 2006, 16, 32-44.

[6] S. J. Loeb, J. A. Wisner, Angew. Chem. Int. Ed. 1998, 37, 28382840.

[7] A. L. Hubbard, G. J. E. Davidson, R. H. Patel, J. A. Wisner, S. J. Loeb, Chem. Commun. 2004, 138-139.

[8] S. J. Loeb, J. A. Wisner, Chem. Commun. 1998, 2757-2758.

[9] a) P. R. Ashton, E. J. T. Chrystal, P. T. Glink, S. Menzer, C. Schiavo, N. Spencer, J. F. Stoddart, P. A. Tasker, A. J. P. White, D. J. Williams, Chem. Eur. J. 1996, 2, 709-728; b) P. R. Ashton, M. C. T. Fyfe, S. K. Hickingbottom, J. F. Stoddart, A. J. P. White, D. J. William, J. Chem. Soc., Perkin Trans. 2 1998, $2117-$ 2128; c) P. R. Ashton, R. A. Bartsch, S. J. Cantrill, R. E. Hanes Jr, S. K. Hickingbottom, J. N. Lowe, J. A. Preece, J. F. Stoddart, V. S. Talanov, Z.-H. Wang, Tetrahedron Lett. 1999 , 40, 3661-3664; d) S. J. Cantrill, D. A. Fulton, A. M. Heiss, A. R. Pease, J. F. Stoddart, A. J. P. White, D. J. Williams, Chem.
Eur. J. 2000, 6, 2274-2287; e) T. Chang, A. M. Heis, S. J. Cantrill, M. C. T. Fyfe, A. R. Pease, S. J. Rowan, J. F. Stoddart, A. J. P. White, D. J. Williams, Org. Lett. 2000, 2, 2947-2950; f) S. J. Cantrill, G. J. Youn, J. F. Stoddart, D. J. Williams, J. Org. Chem. 2001, 66, 6857-6872; g) T. Clifford, A. Abushamleh, D. H. Busch, Proc. Natl. Acad. Sci. USA 2002, 99, 4830-4836; h) S.-H. Chiu, K. S. Liao, J. K. Su, Tetrahedron Lett. 2004, 45, 213-216.

[10] a) D. A. Stauffer, R. E. Barrans Jr, D. A. Dougherty, J. Org. Chem. 1990, 55, 2762-2767; b) J. C. Adrian Jr, C. S. Wilcox, J. Am. Chem. Soc. 1991, 113, 678-680.

[11] a) J. J. Christensen, J. W. Gardner, D. J. Eatough, R. M. Izatt, P. J. Watts, R. M. Hart, Rev. Sci. Instrum. 1973, 44, 481-484; b) M. J. Blandamer, P. M. Cullis, J. B. F. N. Engberts, J. Chem. Soc., Faraday Trans. 1998, 94, 2261-2267; c) J. R. Horn, D. Russell, E. A. Lewis, K. P. Murphy, Biochemistry 2001, 40, 1774-1778.

[12] P. R. Ashton, R. Ballardini, V. Balzani, M. C. T. Fyfe, M. T. Gandolfi, M.-V. Martínez-Díaz, M. Morosini, C. Schiavo, K. Shibata, J. F. Stoddart, A. J. P. White, D. J. Williams, Chem. Eur. J. 1998, 4, 2332-2341.

[13] H. Kamogawa, H. Yamada, Bull. Chem. Soc., Jpn. 1991, 64, 3196-3198.

[14] P. R. Ashton, R. Ballardini, V. Balzani, A. Credi, M. T. Gandolfi, S. Menzer, L. Pérez-García, L. Prodi, J. F. Stoddart, M. Venturi, A. J. P. White, D. J. Williams, J. Am. Chem. Soc. 1995, 117, 11171-11197.

[15] See Supporting Information for details

[16] a) M.-V. Martínez-Díaz, N. Spencer, J. F. Stoddart, Angew. Chem. Int. Ed. Engl. 1997, 36, 1904-1907; b) B. Long, K. Nikitin, D. Fitzmaurice, J. Am. Chem. Soc. 2003, 125, 15490-15498; c) J. D. Badjić, S. J. Cantrill, J. F. Stoddart, J. Am. Chem. Soc. 2004, 126, 2288-2289.

[17] P. R. Ashton, S. J. Langford, N. Spencer, J. F. Stoddart, A. J. P. White, D. J. Williams, Chem. Commun. 1996, 1387-1388.

[18] For other ITC studies of the binding of crown ethers with a variety of guests, see a) R. M. Izatt, K. Pawlak, J. S. Bradshaw, Chem. Rev. 1991, 91, 1721-2085; b) X. X. Zhang, J. S. Bradshaw, R. M. Izatt, Chem. Rev. 1997, 97, 3313-3361; c) V. Rüdiger, H.-J. Schneider, V. P. Solov'ev, V. P. Kazachenko, O. A. Raevsky, Eur. J. Org. Chem. 1999, 1847-1856; d) W. B. Turnbull, A. H. Daranas, J. Am. Chem. Soc. 2003, 125, 1485914866; e) S. I. Pascu, T. Jarrosson, C. Naumann, S. Otto, G. Kaiser, J. K. M. Sanders, New J. Chem. 2005, 29, 80-89.

[19] M. A. Petti, T. J. Shepodd, R. E. Barrans Jr, D. A. Dougherty, J. Am. Chem. Soc. 1998, 110, 6825-6840.

[20] a) SAINT PC Version 6.36, Bruker AXS Inc., 5465 East Cheryl Parkway, Madison, WO, USA; b) SHELXTL PC Version 6.12 and 5.1, Bruker AXS Inc., 5465 East Cheryl Parkway, Madison, WI, USA; SHELX-97: G. M. Sheldrick, Institut für Anorganische Chemie, Tammannstr. 4, 37077 Göttingen, Germany, 1998.

Received: December 4, 2005 Published Online: March 3, 2006 